\title{
A REVIEW OF AMBIENT VIBRATION TECNIQUE ON BRIDGES
}

\author{
Nurul Shazwin Idris ${ }^{1, a}$, Koh Heng Boon ${ }^{2, b}$ and Ahmad Fahmy Kamarudin ${ }^{3, c}$ \\ ${ }^{1,2,3}$ Department of Structural and Material Engineering, Universiti Tun Hussein Onn Malaysia, \\ 86400, Parit Raja, Batu Pahat, Johor, MALAYSIA. \\ anurulshazwin@gmail.com, ${ }^{b}$ koh@uthm.edu.my, ${ }^{c}$ fahmy@uthm.edu.my
}

Keywords: Dynamic characteristic, ambient vibration, natural frequency,

\begin{abstract}
Bridge is one of the important facilities use in daily life as a bridge is built to span physical obstacles such as a body of water, valley or road for the purpose of providing passage over the obstacle. Various testing conducted on the bridge in order to know the dynamic characteristics of the bridges. One of populartesting use isan ambient vibration test. Ambient vibration is a nondestructive test conducted using highly sensitive sensor. This testing iseasy to conduct with less labour, time and also cost. This paper aim to provide up to date literature review on ambient vibration test on bridge includes sources of ambient vibration, procedure of conducting the measurement and results from the ambient vibration test.It is important to known the dynamic characteristics of the bridge especially to determine the dynamic response of the structure and also as dynamic information for seismic design.
\end{abstract}

\section{Introduction}

Ambient vibration also known as microtremor is the excitation experienced by a structure under its normal operating condition [5]. Examples of ambient vibration testexertedon the bridge are traffic vibration, wind, wave motion and seismic excitation. Ambient vibration test conducted to determine the dynamic characteristic of the structure by measuring the vibration behavior using highlysensitive acceleration sensor [18]. The vibration was recorded, evaluated and interpreted under ambient influences without artificial excitation.

Ambient vibrationtest widely applied to different types of bridges such as a double-deck bridge [6], pre-stressed concrete box girder bridge [2,4], continuous girder bridge [12], reinforced concrete bridge [16], cable stayed bridge [12] and stone masonrybridge [9] in orderto determine the dynamic characteristics of the bridge. It is desirable to measure the dynamic characteristicsfor both newly constructed bridge and for the existing bridge, it in term of natural frequencies, mode shape and modal damping of the bridge to understand better their dynamic behavior under normal traffic loads an also during extreme loads such as those caused by seismic events or high wind [4].

From previous earthquake in Loma Prieta, USA (1989), Kobe, Japan (1995), Izmit, Turkey (1999), Chi-chi, Taiwan (1999)hasresulted the extensive damage to transportation facilities such as bridges[7]. Theseeventsshow that bridges could be vulnerable under dynamic loading [12]. Therefore, this paper aim to provide up to date literature review of ambient vibrationtest on bridge includes sources of ambient vibration, procedure of conducting the test and the test results.

The ambient vibration testhas been used for many studies because of many reasons such as simplicity in procedure, relatively fast, low-cost consuming and no disturbance of the traffic when carrying out the test [7]. Besides, this testing is a non-destructive and easy to be conducted with less labour.

\section{Sources of Ambient Vibration}

Ambient vibration sources are divided into free vibration and force vibration. All sources collectedusing highly sensitive acceleration device sensor such as seismometer and accelerometer. Seismometer collected ambient vibration from free vibration sources, whereas accelerometer collected ambient vibration from both free and forces vibration sources. Generally it was accepted that seismometer are more reliable to record ambient vibration. The advantages of free vibration 
sources are the sources represented the actual operating conditions of the structure which vibrates under its natural excitation loads such as traffic, winds, and microtremors [16]. This paper is focusing on ambient vibrationtest from free vibration sources using seismometer sensor.

\section{Procedure of Conducting Ambient VibrationTeston Bridge}

Basically ambient vibration tests conducted using several sensor units, cable and main body that contains amplifiers and A/D (analogue to digital) converter known as data logger or measurement station and a notebook personal computertype. Ambient vibration collected using a sensitive sensor and all the vibration data saved into the data logger.The sensor mainly used in the civil infrastructures and particularly for soil record. All the vibration data from the data loggeranalyzed using specific software such as Geopsy, ARTeMIS Extractoror other supported software. Fig. 1 shows devices used for the ambient vibration test.

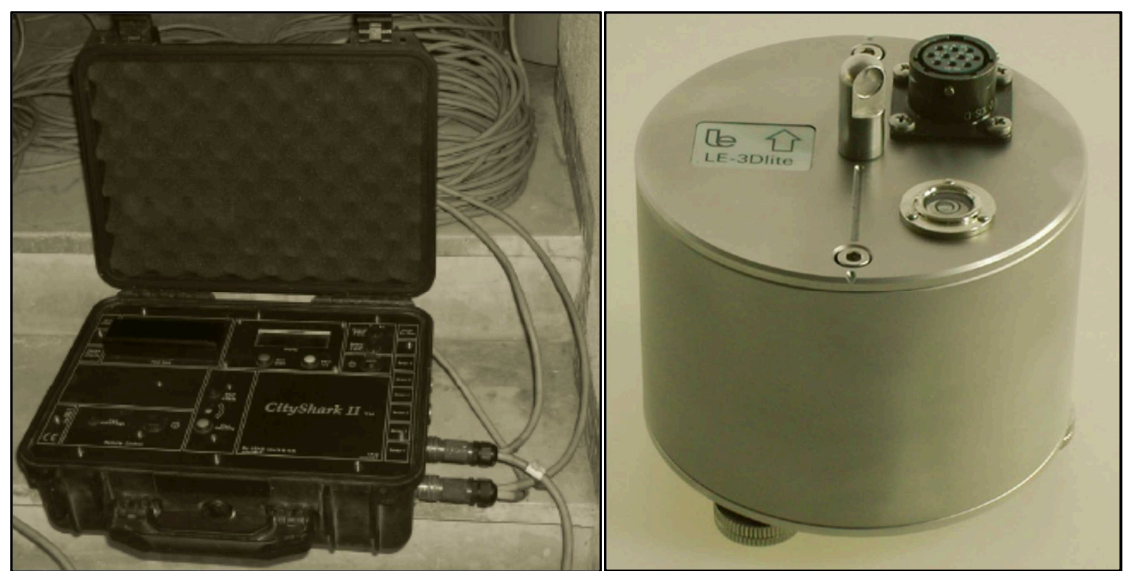

Fig. 1: CityShark II data logger and seismometer Lennartz LE3Dlite [1]

Ambient vibration tests conducted with installation of sensors at different locations on the bridge deck and all real time response data recorded through the data logger simultaneously. Depend on number of sensors used. Fig.2shows the location of eight units of sensor for ambient vibrationtest. Each testconducted for 15-30 minutes [7]. The longer recording times increase the amount of usable data. For every testambient vibrationcollected from three directions which are vertical $(Z)$, lateral (NS) and longitudinal (EW) direction. The sampling frequency varies from 10-100 Hz according to selected rate.

There are no specific method or guidelines to conduct ambient vibration tests on the bridges, but some interest needs to be concerned as describe in Wenzel \& Pichler[18]:

1) The acceleration sensors must be arranged in such a way that a sufficient number of points along the system lines of the structure to be examined is covered for the determination of the mode. In particular, inconstant points (joints and coupling spots) need to be instrumented.

2) Sensor are repeatedly rearranged, with reference sensor always remaining on the same spot in order for the individual signals to refer to each other and. The reference sensor positions need to be considered as to obtaina clear reference signal for the identification of higher natural vibration form.

3) The midpoints of the main field are unsuitable as reference locations because a node often already exists at the second vertical bending vibration point.

4) It is advantageous if the tests are carried out at the both sides of the structure in order to be able identify torsion modes clearly.

5) It is sufficient to have sensor working in parallel in order to obtain information regarding the vibration behavior at the corresponding Eigen frequency. 


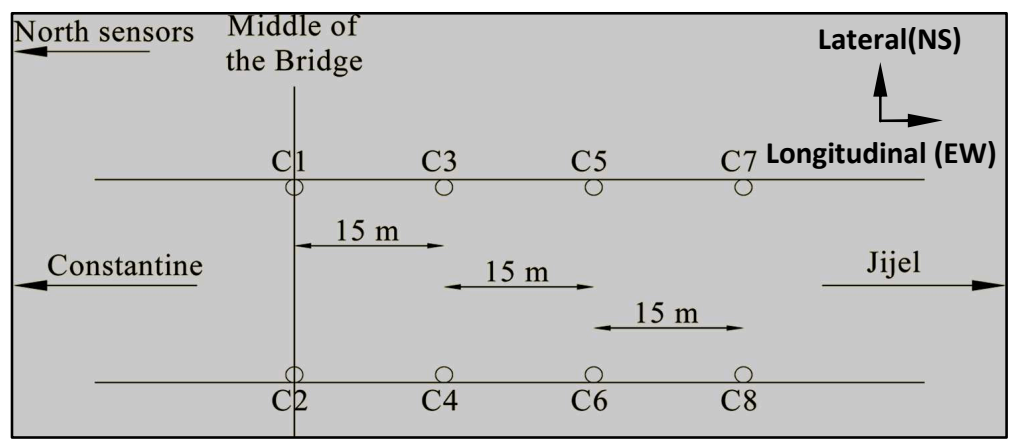

Fig. 2: Location of sensor for ambient vibrationtest [7]

\section{Result from Ambient VibrationTest}

The analysis response of the bridge to ambient vibration consisted of computation of Fourier spectra for different window taken from the response signal. Responses signal from ambient vibrationtest enables prediction of the bridge dynamic characteristic in term of natural frequencies. Fig. 3 shows an example of waveform from bridge testing on Mila-Algeria cable stayed bridge.

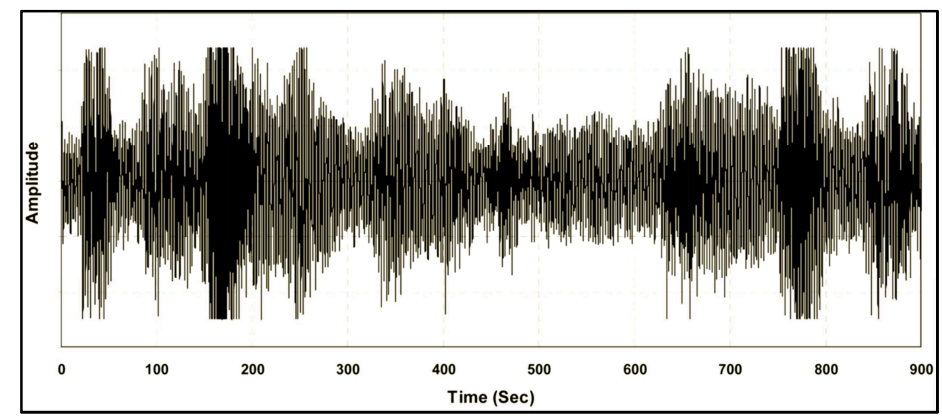

Fig. 3: Recorded ambient vibration on bridge [7]

The dynamic response analyzed by selecting windows from the recorded signal. The signal must approach as much possible the characteristic of a white noise record. Spectral amplitude for each window was computed through Fourier transform. Computed spectra are smoothed through a sliding window which the form and the width depend on the frequency [8]. Finally, the obtained spectra are averaged and their standard deviation determined.

The recordsignals enable the identification of the bridge natural frequencies $(f o)$. Natural frequencies $(f o)$ can be obtained by locating the peaks corresponding to maximum responses as illustrated in Fig 4.The mode of frequencies of the tested bridge obtained through the record at different location peaks [2,7]. From the mode of frequencies, the identification of vibration mode shape can be obtained for each natural frequency. The mode shape corresponds to the deflected shape when the structure vibrating at that frequency [14]. 


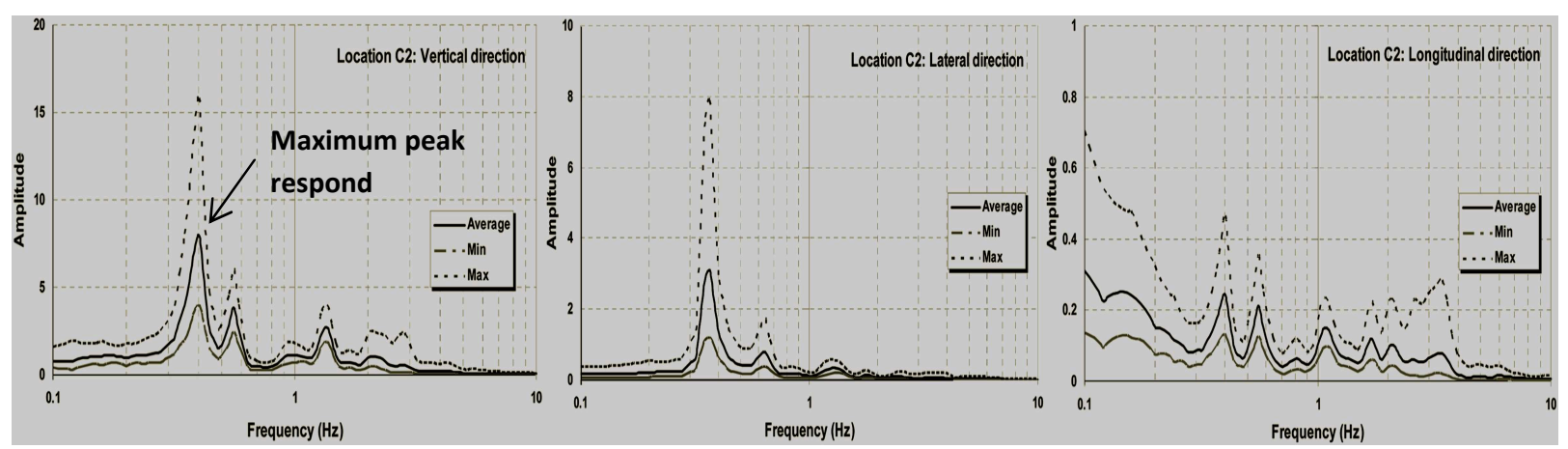

Fig. 4: Fourier spectra on bridges for vertical, lateral and longitudinal direction [7]

From the example above its shows six modes of frequencies were identified in the range 0 to $1 \mathrm{~Hz}$. The first vertical mode is $0.36 \mathrm{~Hz}$ and the first longitudinal mode is $0.38 \mathrm{~Hz}$ and the first mode lateral is $0.39 \mathrm{~Hz}$. Table 1 shows experimental natural frequencies of the bridge. To confirmed the result from ambient vibration is acceptable, most of the researcher use finite element modeling to compare the natural frequency values.

Table 1: Identified experimental natural frequencies [7]

\begin{tabular}{|c|c|c|}
\hline Mode & Frequencies $(\mathrm{Hz})$ & Direction \\
\hline 1 & 0.36 & Vertical $(\mathrm{Z})$ \\
\hline 2 & 0.38 & Longitudinal $(\mathrm{NS})$ \\
\hline 3 & 0.39 & Lateral $(\mathrm{EW})$ \\
\hline 4 & 0.56 & Lateral $(\mathrm{EW})$ \\
\hline 5 & 0.55 & Longitudinal $(\mathrm{NS})$ \\
\hline 6 & 0.63 & Vertical $(\mathrm{Z})$ \\
\hline
\end{tabular}

\section{Conclusion}

It can be concluded, by using ambient vibration, dynamic behavior of the bridges in term of mode of frequency can be determined.Identification of dynamic characteristic is important to predict the dynamic response of the structure and also as dynamic information for seismic design

\section{Acknowledgement}

A lot of thank to my supervisor who improvise us in doing this paper and also to my entire beloved lecturer, friend and especially for my family to support and encourage me to finish this paper.Lots of thank also to Universiti Tun Hussein Onn Malaysia in providing the financial support for this research.

\section{References}

[1] Chatelain, J., Guillier, B., Guéguen, P., Fréchet, J., \& Sarrault, J. (2012). Ambient Vibration Recording For Single-Station, Array And Building Studies Made Simple: Cityshark II, International Journal of Geosciences. 2012. 3 (6A): 1168-1175.

[2] Citak, S. O., Ohori, M., \& Nakamura, T. (2012). Microtremor Measurements And Earthquake Response Analysis On Urado Bridge, 15 WCEE LISBOA, Kochi, Japan.

[3] Duval, A., Chatelain, J., \& Guillier, B. (2004). Influence Of Experimental Condition For « HV » On Ambient Noise, Vibration Method. 13th World Conference on Earthquake Engineering, Vancouher, Canada: 306. 
[4]Farrar, C.R., \& James III, G. H. (1997). System Identification From Ambient Vibration Measurements On A Bridge. Journal Of Sound And Vibration. 205, 1-18.

[5]Farrar, C.R, Duffey, T. A., Cornwell, P. J., \&Doebling, S. W. (1984). Excitation Methods ForBridge Structures. 1063-1068.

[6] Harik, I.E., Allen, D.L., Street, R.L., Guo, M., Harison, J., \& Gawry, M.J. (1997). Free And Ambient Vibration Of Brent-Spence Bridge. 1262-1268.

[7]Kibboua, A., \& Farsi, M. N. (2008). Modal analysis and ambient vibration measurements on Mila-Algeria cable stayed bridge. 29(2): 171-186.

[8] Konno, K. and Ohmachi, T.(1998).'Ground-Motion Characteristics Estimation from Spectral Ratio between Horizontal And Vertical Component Microtremor", Bull Seismol.Soc.Am. 88(1), 228-241

[9]Krstevska, L. S., Kustura, M., \& Tashkov, L. A. Experimental In-Situ Testing Of Reconstructed Old Bridge In Mostar, The 14th World Conference On Earthquake Engineering. October 12-17. Beijing, China. 2008. 1-8.

[10]Negulescu, C., Luzi, G., Crosetto, M., Raucoules, D., Roullé, A., Monfort, D., Pujades, L., Colas, B.,\&Dewez, T. (2013). Comparison Of Seismometer And Radar Measurements For The Modal Identification Of Civil Engineering Structures. Engineering Structures, 51, 10-22.

[11] Ren, W., Peng, X. \& Lin, Y. (2005). Experimental And Analytical Studies On Dynamic Characteristics Of A Large Span Cable-Stayed Bridge. Engineering Structures, 27(4), 535-548.

[12] Ren, W., Zatar, W., \& Harik, I. E. (2004). Ambient Vibration-Based Seismic Evaluation of a Continuous Girder Bridge, 26, 631-640.

[13] Sherif, B., Liam, W., \& Quincy, T. M. (2013). System Identification Of A 13-Story Reinforced Concrete Building Through Ambient And Forced. $4^{\text {th }}$ ECCOMAS ThematicConference On Computational Methods In Structural Dynamics And Earthquake Engineering.Kos Island, Greece.

[14] Salawu, O. S., \& Williams, C. (1995). Review Of Full-Scale Dynamic Testing Of Bridge Structures. Engineering Structures, 17 (2), 171-186.

[15] Siringoringo, D. M., Fujino, Y., Asce, M., \&Nagayama, T. (2013). Dynamic Characteristics OfAn Overpass Bridge In A Full-Scale Destructive Test, Journal Of Engineering Mechanic,139, 691-701.

[16] Smaoui, H., Cherif, F., Bahlous, S., \&Ghrairi, A. (2004). Modal Identification And Finite Element Model Updating Of A Reinforced Concrete Bridge, 9 (2), 29-34.

[17] Uehan, F., \& Meguro, K. (2000). Vulnerability Evaluation Of Jacketed Viaduct Using Microtremor Measurement \&Numerical Simulation, 1-8.

[18] Wenzel, H., \& Pichler, D. (2005). Ambient Vibration. Unite Kingdom: John Wiley \& Sons, Ltd. 